\title{
DEATH AND DIGNITY - THE WORK OF A FUNERAL DIRECTOR
}

\author{
David Ireland and Paul Wilson, Funeral Directors \\ Preston Ireland Bowker, Queen Street, Lancaster
}

\section{INTRODUCTION}

Whenever and however it arrives, death is a time of peace for a deceased person. The end of sentient existence is in marked contrast to the turmoil endured by relatives and friends. There is a practical need to dispose of the remains which occurs when the living are vulnerable, upset or distraught, usually ignorant of the law and frequently unfamiliar with the means of honouring the deceased person and saying farewell. Regardless of the events prior to death and the cause of death, families need to take action and make many decisions in only a few days.

Funeral directors provide an important service for the next of kin by making funeral arrangements and giving support. They act as agents for the family, guiding them through events and offering appropriate support and friendship. In the interval between death and burial they are the temporary custodians of the final human form of a life which has usually been cherished by many people. It is a sensitive profession, often the butt of humour and derision, but the people who do this work are dedicated and caring.

There is much that doctors can do to assist families, not the least of which is prompt attention to statutory documentation. The following is a guide.

\section{HISTORY}

"The laying out of the body, the burial rites are more of a consolation to the living than assistance to the dead." $\mathrm{St}$ Augustine (354-430 AD)

Before the Victorian age, burials occurred in parish churchyards at the discretion of the incumbent of the church. No deeds were issued and there were no rights of burial other than residence in a parish. The Burial Laws Amendment Act of 1880 allowed burial in consecrated ground without the Church of England service (and in unconsecrated ground with the service) so long as 48 hours' notice in writing was given to the incumbent or registrar, thus giving freedom of burial rights. Cemeteries were usually set out in three sections, one for Church of England, whose graves were consecrated in advance by a bishop, one for Roman Catholics, where each new grave was blessed at the time of burial, and one for nonconformists, who had no such requirements.

With the Victorian era came the large civic cemeteries and the need for more documentation. Graves were numbered and deeds of exclusive right of burial issued by the authorities. Around this time, funerals became more organised and dignified. The hearse became a glass-sided coach with ornate work and ostrich plumes, drawn by a team of black horses.
The bearers would be in black and the funeral director would wear a top hat with black ribbons, and a tail coat. The origins of funeral firms were mainly from two specific sources: carriage masters who had vehicles and horses, and joiners who had the ability to manufacture coffins. Our own company consists of both these: T Ireland \& Son Ltd (1870) were carriage masters, and Thomas Preston \& Sons (c1820), William Bowker \& Sons Ltd and R Wilson \& Sons (1839) were all local joinery businesses. With the advent of the motor vehicle, the hearse evolved to its present shape, along with the limousine to carry mourners.

The Cremation Society of Great Britain was formed in 1874 and the first crematorium opened at Woking in 1885. By the end of 1905 thirteen were in operation. The Cremation Act of 1902 empowered local authorities to provide and maintain crematoria; there are now 226 operating in the UK.

\section{THE IMPORTANCE OF DOCUMENTATION}

In all straightforward cases the medical practitioner issues the Medical Certificate of the Cause of Death, which the family takes to the registrar and obtains the Certificate of Disposal, which is handed to the funeral director. This certificate is handed to the person in charge at a cemetery, or minister in charge of a churchyard at the time of the funeral. In cases where a coroner is involved, he will issue Form 100 after postmortem for registration giving cause of death, or in the case of an inquest, a Coroner's Order for Burial issued after the inquest has opened and been adjourned.

The speedy completion of medical certificates is paramount in the arrangement of funerals. Firstly, the funeral director and family need to fix a day. Secondly, to enable the deceased to be removed from the hospital mortuary, in the case of a hospital death. Thirdly, to register the death and to obtain the Certificate of Disposal, and give the funeral director the necessary authority to deal with the deceased.

The final aspect of documentation is to round off the funeral. On each type of certificate, Coroner's or Disposal, there is a return slip which is sent to the registrar by the crematorium or burial authority, which gives the date of final committal.

If embalming is necessary, this has to be carried out as soon after death as possible. Certificates B, C and $\mathbf{F}$ and Cause of Death should be prioritised and the family must obtain the disposal certificate from the registrar.

Statutory documentation for cremation is as follows:

For a death certified by a general practitioner or hospital doctor - 


\section{Form A (Application Form)}

To be completed by executor or next of kin.

\section{Form B (Medial Certificate)}

Certificate of medical attendance signed by a registered medical practitioner who has attended the deceased during the last illness and can certify the cause of death.

\section{Form C (Confirmatory Medical Certificate)}

Certificate signed by another registered medical practitioner of at least five years' registration, not related to the deceased or a partner of the doctor who signed Form B.

If the deceased has a pacemaker or radioactive implant this must be surgically removed as an explosion could occur.

In the case of a hospital autopsy agreed by the relatives of the deceased only one medical practitioner (as described above in Form C) completes Form B only.

The relatives or executor of the deceased takes the Certificate of Cause of Death to the registrar, registers the death and obtains the Certificate of Disposal, which is passed to the funeral director.

The funeral director completes an instruction form to the crematorium confirming time, religion, music and instruction as to ultimate disposal of cremated remains. The funeral director has then to convey forms A, B, C, Disposal Certificate and Instruction Form to the crematorium the day before the funeral. The medical referee of the crematorium authority scrutinises the forms and, when approved, signs Form F, the authority to cremate. If he is not happy with any aspect of the paperwork, he has the power to refuse cremation and refer to the coroner. In the event of any death being reported to the coroner, forms $\mathbf{B}, \mathbf{C}$ and $\mathbf{F}$ are replaced by the Coroner's Certificate $\mathbf{E}$ for cremation, issued after postmortem and cause of death established. Also Form 100 is issued, notifying the registrar of the cause of death. Form 100 is also issued in cases where the coroner has been informed but considers the case does not require postmortem. In this instance, $\mathbf{B}, \mathbf{C}$ and $\mathbf{F}$ should also be completed.

If an inquest is necessary, the coroner will open the inquest after postmortem and adjourn it to allow the funeral to take place. In this case the coroner will issue Certificate $\mathbf{E}$ for cremation and he will register the death after the full inquest.

In this country cremation occurs in approximately $70 \%$ of all funerals.

\section{EXCEPTIONAL CASES}

Burial at sea This is treated as a removal from the country and requires the coroner to be informed, and an Out of England Order issued. If the burial is within UK coastal waters, the Ministry of Agriculture and Fisheries must be informed to check that tides will not return the coffin to the shore.

Burial on private land This requires the approval of the Home Office, the relevant land owner and the district council. The site must be over 200 yards from a water course.

Anatomical examination Usually a teaching hospital will accept bodies if bequeathed within a 50-mile radius of the hospital. When the body is of no further use the hospital will pay for a simple basic funeral. In these cases, speed of issue of the death certificate is imperative, as removal to the hospital needs to be done quickly.

\section{Forms required}

Form AA7 To inform the Department of Anatomy of the death and allow the removal of the deceased.

Form AA4 The Medical Certificate of the Cause of Death issued by the doctor who had issued the original.

Form AA2 This informs the Inspector of Anatomy, DSS London and authorises the removal of the deceased for anatomical examination.

If cremation is required afterwards Form $\mathbf{A}$ must be signed by the family.

Removals for funerals abroad This requires the death to be registered and the coroner informed. He will issue an Out of England Order. Documents must travel with the deceased i.e. Out of England Order, copies of Death Certificate, Certificate of Embalming and for some countries a certificate of "free from infection" is required. Form FF1 is issued by the Medical Officer of Health for the region where the death took place. Consular requirements and airline regulations must also be observed.

\section{THE ROLE OF THE FUNERAL DIRECTOR}

The funeral director has to be advisor, friend, confidante and master of ceremonies to a bereaved family. He must show empathy with their situation and a confidence that whatever their problems, he is a professional who can deal with them.

The modern funeral director will have premises where the family feels comfortable and Chapels of Rest which are private, allowing quiet undisturbed time with their loved ones. At all times staff must conduct themselves with caring consideration and handle the deceased with dignity.

\section{Removal from a hospital}

Identification is paramount as a mistake could be disastrous. After death in hospital the deceased is conveyed to the mortuary and the name is registered. When funeral staff are instructed to collect the body, they must first check the hospital identity tags and check any jewellery against the mortuary register. Our staff apply our company's identification tags and sign them. When satisfied about the identity, they hand over the release form signed by the family to the mortuary attendant and carefully lift the deceased from the mortuary tray onto their stretcher or into a coffin. The funeral staff then sign the mortuary register and return to the funeral home.

As a company we have equally stringent regulations. On arrival, the deceased's details must be entered in our mortuary register, noting jewellery and personal belongings. At all times when moving the deceased, identity is checked and staff must sign the identity tag. It is the funeral director's ultimate responsibility to make a final check of the identity before setting off to the funeral.

\section{Removal from a private home}

This is one of the most sensitive times in the funeral process. 
Most funeral directors have a removal vehicle such as a van, private ambulance or estate car with darkened windows. It is not considered a good thing to take a hearse to the house. The removal team works under the supervision of the funeral director, who will try to keep the family in another room as it is difficult to lift a body with dignity, however careful we are. Also, if the deceased is upstairs or in an awkward room and we are using a stretcher, we need to fasten restraining belts. If the family insists on being present, simply working quietly with dignity is the best we can do.

Removing the deceased person from the home is a very emotional time for the family. An assurance that they can come to the Chapel of Rest as soon as possible is a kindness and is often helpful.

At a home removal, identification is essential, as are instructions about jewellery, clothing etc. It is also necessary to carry out first offices if there has been incontinence. These may include washing, cleaning and plugging orifices to prevent recurrence when moving. Removal staff should be equipped with all the necessary protective clothing, gloves, bio-hazard packs and disaster bags. The death may have been violent, a suicide or the result of fire. We are equipped for every eventuality and aware of the possibility of AIDS and needles where addicts are concerned.

The medical condition of a person is not always known by the doctor who is called out by the police to a sudden death, so we must treat all cases as hazardous.

\section{CARE OF THE BODY}

When we receive a body into our care and all documentation is complete we need to assess whether embalming is required. This is dependent on the condition of the body and the interval before the funeral.

Body fluids are extracted from the stomach and chest cavity with the use of a trocar, which is a hollow perforated rod with a sharp point with a rubber tube attached to a suction pump. When emptied, the cavities are filled with a strong formaldehyde solution. The body's circulatory system is pumped through with a pink arterial fluid via the carotid or femoral artery. This gives the deceased a natural body colour and dissipates any hypostasis.

Embalming eliminates any unpleasant odours and sanitises the body, and certainly gives a more natural look when the family is viewing.

Presentation of the body is one of the most essential parts of the funeral director's work. In most cases, they will not have known the deceased, and it is preferable if the family can provide a recent photograph showing hairstyle, and whether the person had a beard or moustache.

Simple things like this can drastically alter a person's appearance and destroy the good relationship you have had with a client. If the deceased was female, hair, make-up and jewellery are important. The deceased always look more natural in their own clothing. If not available, they are dressed in a gown or nightdress.

It is always left to the family to decide if they wish to view. If for any reason viewing is not possible (such as disfigurement or severe deterioration) we find it can help a family to sit in the chapel by the closed coffin. It is often the moments in a Chapel of Rest that bring home the reality of death and emotions are released for the first time.

\section{THE FUNERAL}

All the work of documentation, preparation and liaison culminate in the funeral itself. The funeral director acts as master of ceremonies and needs to be aware of all that is happening. He will need to be calm and give assurance to the mourners that all is well, even if everything is going wrong, i.e. hold-ups in traffic, service over-running, mechanical failure, floral tributes not arrived. The funeral is a stagemanaged and dignified last tribute to the deceased, which if carried out properly will give comfort to the family.

The funeral of a child makes the greatest demands on a funeral director. The parents are utterly shocked and very rarely able to think about arrangements. Nothing you can say or do seems to be adequate to ease their grief. In the midst of anger, frustration, remorse or withdrawal from reality a funeral still has to be arranged.

More often than not a grandparent, brother or sister of the parents will help, but one has to be careful not to pre-suppose the parents' wishes. It is better to leave unresolved matters and let the family discuss them privately.

The funeral director and his staff are also personally affected by a child's death, often because of their own children. To have to coffin and dress a child is a very hard thing to cope with.

\section{CHARITABLE DONATIONS}

The funeral director is called upon to handle charitable funds donated in lieu of flowers. Over a year this can amount to many thousands of pounds. If the family is unsure of the fund, we can advise of a suitable charity. We are in touch with all organisations and if the deceased was in hospital we advise the relatives of funds run by the Trust. We forward the monies to the chosen fund and provide the family with a list of donors. All donation accounts must be recorded and sent for scrutiny if required.

It is disturbing fact that anyone can set up in this business without qualifications, and practise immediately. Fortunately the recognised companies belong to a professional organisation, the National Association of Funeral Directors, with a code of practice, a diploma and a nationwide network of branches which meet regularly.

\section{PRE-ARRANGEMENT SCHEMES}

The 1980s saw the advent of pre-arrangement as a development in the funeral trade. Costs had risen dramatically across the whole of the profession, which gave concern not only to the public but also to ourselves.

The idea of payment in advance for a funeral was attractive to clients as an obvious saving for their family, and to ourselves as a way of securing business for the future.

In the 1990s nearly all funeral firms run a scheme of this kind. In order to secure the fund and to protect the clients' interest, the major pre-need companies invest the money in a trust fund managed by a bank as custodian trustees. This 
gives the client a guarantee and is the method approved by the Office of Fair Trading.

We have found by experience that pre-arranging relieves a person of fears that his savings may not last, and provides the opportunity to state funeral requirements, which is a help to the relatives.

\section{COMMON MISUNDERSTANDINGS AND MYTHS}

The funeral profession is a target for misguided comments, such as "they re-use the coffins after a cremation." By law, a committal at a crematorium is exactly the same as burial in a grave, although once the curtains are closed, the coffin is not placed in the cremator immediately. It must not be interfered with in any way. The lid is screwed down at the funeral home and is never removed. The coffin and its contents are cremated. The family has a legal right to witness cremation if desired.

This myth has evolved from the sight of a hearse or removal vehicle appearing from the rear of a crematorium, perhaps with a covered coffin. This will be an 'out of town' funeral director who has collected the deceased and the relevant forms from hospital and is taking them in to the crematorium for scrutiny by the medical referee. In all fairness this is an emergency measure, used only when time is short, but it only requires one instance to spark a rumour.

Another popular myth is that you do not get the remains of your loved one. People seem to believe that ashes are piled together and mixed. This is strictly not the case: each coffin is individually cremated and a card with all details follows the remains until they are reduced to fine ash, when it is attached to the single container. The only things removed are coffin nails and screws, artificial hip joints and similar, which are sifted out from the remains.

A commonly held view about burial is that you have to purchase a grave. This is not so: what you have purchased is the right of burial within a plot by deed, but the land still belongs to the burial authority. Burial within a plot in a churchyard is at the discretion of the incumbent of the church. Your only right is that of burial in an Anglican churchyard if you reside within the parish, irrespective of your religion. Even that right can be over-ridden: if space is short, the vicar may decide to reserve it for regular parishioners.

\section{SUMMARY}

The funeral director and his staffwork 365 days a year, 24 hours a day, with measures to cope with any eventuality. They need a funeral fleet, removal vehicle, funeral directors' cars, offices, Chapels of Rest and a constantly-manned telephone.

It is a highly stressful job which puts pressure on home life and restrictions on leisure. It is, however, one of the most rewarding occupations to be in.

\section{BEREAVEMENT ORGANISATIONS}

Compassionate Friends

6 Denmark Street

BRISTOL

BS1 5DQ

CRUSE Bereavement Care

126 Sheen Road

Richmond

Surrey

TW9 1UR

Foundation for the Study of Infant Deaths

15 Belgrave Square

LONDON

SW1X 8QB

National Association of Bereavement Services

c/o 68 Charlton Street

LONDON

NW1 1JR

Miscarriage Association

18 Stoneybrook Close

West Bretton

WAKEFIELD

WF4 4TP

Samaritans

17 Uxbridge Road

SLOUGH

Berkshire

SL1 1SN

Terence Higgins Trust

BM AIDS

LONDON

WC1N 3XX

Stillbirth and Neonatal Society

28 Portland Place

LONDON

W1N 3DE

\section{USEFUL READING}

The law of burial. Alfred Fellows

The law of burial, cremation and exhumation. MRR Davies

The disposal of the dead. CJ Poison, RP Brittain, TK Marshall

\section{Through grief. Elizabeth Collick, pub CRUSE}

Facing grief - bereavement and the young adult. Susan Wallbank, pub CRUSE

The early days of grieving. Derek Nuttall, pub Beaconsfield

A grief observed. CS Lewis, pub Faber

What to do when someone dies. Consumer Association, PO Box 44, Herts SG14 1SH

Helping ourselves. Excerpts from Compassionate Friends selected by Audrey England, available from Compassionate Friends 